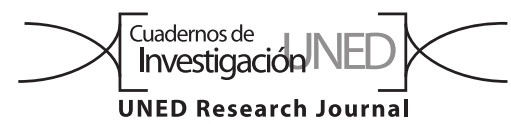

\title{
Perceptions of the use and value of fungi by two groups of young adults from Central America
}

\author{
Carlos Rojas Alvarado', Sergio Molina-Murillo² \& Robin G. Doss ${ }^{3}$
}

1. University of Costa Rica, Engineering Research Institute and Department of Biosystems Engineering, San Pedro de Montes de Oca, 11501

Costa Rica; carlos.rojasalvarado@ucr.ac.cr, https://orcid.org/0000-0002-7968-4833

2. Universidad Nacional, Department of Environmental Sciences, Heredia, 40101 Costa Rica; sergiomolina@una.ac.cr, (iD) https://orcid.org/0000-0002-3276-000X

3. Independent researcher. Apdo. 186-3100, Santo Domingo de Heredia, 40306 Costa Rica; robin.g.doss@gmail.com, (D) https://orcid.org/0000-0002-7829-9757

\author{
Received 01-IV-2019 • Corrected 20-VI-2019 • Accepted 04-VII-2019
}

DOI: https://doi.org/10.22458/urj.v11i3.2619

\begin{abstract}
Introduction: Integrated efforts for the management and conservation of natural resources require the availability of socio-cultural information. However, perceptional studies are rarely used along with biological data to design methodologies of biodiversity conservation. Objective: To explore the potential of perceptional information on fungi as a tool for developing culture-sensitive methods of management and conservation. Methods: Through a survey-based design, ethnomycological information from urban settings in Honduras and Costa Rica was collected and evaluated for a group of young adults (16-25 years old, N=615 surveys). Results: Fungi were not perceived to have the value of plants and animals, in both countries. The latter were mentioned as preferred by $74 \%$ of respondents. By country, $39 \%$ of Costa Ricans mentioned the most important use of fungi to be food, whereas $58 \%$ of Hondurans responded a medicinal application. Remarkably, $27 \%$ of respondents in Costa Rica mentioned that fungi are important in ecological processes, much higher than Hondurans with only $7 \%$. Conclusions: Exposure to formal education or previous cultural background may not play such an important role in shaping perceptions of the group of fungi as it does social aspects associated with the city lifestyle in the populations studied.
\end{abstract}

Key words: Conservation, Costa Rica, functional diversity, Honduras, monitoring, natural capital.
RESUMEN: "Percepción del uso y valor de los hongos en dos grupos de adultos jóvenes de América Central". Introducción: Los esfuerzos integrados de conservación y manejo de los recursos naturales requieren información sociocultural. Sin embargo, estudios de percepción son raramente utilizados junto con datos biológicos en el diseño de metodologías de conservación de biodiversidad. Objetivo: Explorar el potencial de la información de percepción que existe hacia los hongos como una herramienta sensible culturalmente para el desarrollo de métodos de manejo y conservación fúngica. Métodos: Por medio de una encuesta se recolectó información etnomicológica en poblaciones urbanas jóvenes de Honduras y Costa Rica (16-25 años, N=615 cuestionarios). Los patrones de respuesta fueron comparados y contrastados. Resultados: Los hongos no fueron percibidos con el valor de las plantas o los animales en ambos países. Estos últimos grupos fueron mencionados como preferidos por el $74 \%$ de los participantes. Por país, $39 \%$ de los participantes en Costa Rica mencionaron que el más importante uso de los hongos es comida, mientras que el $58 \%$ en Honduras respondió una aplicación en medicina. Notablemente, el 27\% de los participantes en Costa Rica mencionó que los hongos son importantes en procesos ecológicos, mucho más que los hondureños con solo 7\%. Conclusiones: La exposición a la educación formal o el acervo cultural no jugaron un papel tan importante en las poblaciones estudiadas para determinar la percepción hacia los hongos como sí lo fueron factores sociales asociados a la vida en ciudades.

Palabras clave: Capital natural, conservación, Costa Rica, diversidad funcional, Honduras, monitoreo, capital natural.
Perceptional studies on natural resources are rarely implemented as part of a regular policy of resource management. Even though there is good evidence pointing out that the application of multidisciplinary approaches (Parker, 2011; Larson, De Freitas, \& Hicks, 2013) for true conservation is key for the success of these programs, socioeconomic or cultural studies are infrequently considered in the planning process. The latter is relevant because the interaction between societies and natural resources is influenced by historical and cultural elements and because the intensity and directionality of such interaction is very dynamic over time (Lennox, 
2010). In this manner, this interaction may not be measured by objective indicators alone (Diedrich \& GarciaBuades, 2009) and requires constant reinterpretation.

In biodiversity hotspots, where biological resources should be a priority in the conservation agendas, detrimental processes on such biodiversity have been extensively documented (Brooks et al., 2002). However, despite social studies (Cohen, 2003) suggesting drastic changes in cultural constructions across human societies by the mid part of the 21st century, projects incorporating social perception and behavioral integration towards natural or biological resources are still rare. In this manner, the conservation of nature still seems to be a topic of the natural sciences and not an integrated issue of the human lifestyle. This paradigmatic approach is risky due the potential negative effect on the functionality of ecosystems (Naeem, Duffy, \& Zavaleta, 2012) based on lack of knowledge by the populations that interact with natural resources.

In the heart of the Mesoamerican Biodiversity Hotspot, Central America is characterized by both its natural and cultural richness (Hall \& Pérez Brignoli, 2005; Jopa et al., 2011). As a natural bridge between the two main land masses in the Americas, this region is recognized to have been the point of confluence of important pre-Columbian civilizations and overlap area for distributional patterns of species (Cooke, 2005). This region is not only multicultural but biologically rich and deserves to be studied in an integrated manner.

Mesoamerican fungal diversity has been suggested to represent up to $13 \%$ the total biodiversity of some areas such as Costa Rica (Obando, 2007), only after insects, but yet few ethnomycological studies targeting non-indigenous populations have been carried out in this region. This observation suggests a conceptual issue in Central American populations since fungi comprise one of the most important groups of organisms for the life on the planet (Lange, 2010). For these reasons, our objective was to document and contrast the perception that two urban educated social groups in different cultural areas of Central America have towards fungal resources.

\section{MATERIALS AND METHODS}

This study was carried out in Costa Rica and Honduras between 2012 and 2013 as part of a diagnostic project on mycological knowledge in the general population of Central America. Even though both countries are located in the Mesoamerican region, Honduras is located within the fungi-loving area influenced by Mayan cultures whereas the central and southern sections of Costa Rica (including the metropolitan area) are located in the region of influence of South American Chibcha cultures, mostly mycophobic (see Gómez, 1983). The mycophilic character of Honduras may be supported by the widespread use of the regional word choro in addition to the common Spanish word hongo to refer to fungi in urban areas and in terms of the Festival Nacional del Choro, an event clearly inexistent in Costa Rica. As such, our working hypothesis was that perceptional views on fungal resources in urban areas, influenced by culture-driven traits, could be documented across both countries in presumably homogeneous population groups. The latter follows previous ethnological observations recorded by Boa (2004) and was intended to provide information for contextual management of fungal resources in the two regions under study.

A structured questionnaire was developed and tested to collect the information analyzed in this investigation. Respondents between 16-25 years, from both countries, were randomly selected by survey-takers, who informed the purpose of the study. The survey was anonymous and individually answered in a voluntary manner. A total of 615 surveys were conducted within the metropolitan capital areas of both countries. Out of the total number of surveys, 290 were carried out at the University of Costa Rica, and 325 at the National Autonomous University of Honduras. In both cases, surveys were given to participants independently of their relationship with these institutions, and the venues were simply used as standard geographical locations between countries. Since information management is obviously not a function of formal education, this study also evaluated the myth of higher thematic literacy in educated populations, understanding education as access to university-level formal training.

The questionnaire was written in Spanish and contained questions of perceptional constructions related to fungal resources. The instrument contained open-ended and closed-ended questions in which answer options were provided. In order of appearance the questions considered in this study were: Do you know what a fungus is? What is your first mental association after hearing the term fungus? Do you think fungi are interesting? Do you think fungi are important for the planet? How would you rank in order of importance the following groups: fungi, plants, animals? And finally, in your opinion what is the most important use of fungi? Socio-demographic questions including sex, age, and educational level were also recorded for all participants.

A dataset was created with all the answers followed by a filtering process in order to remove inconsistencies 
such as wrong entries. For closed-ended questions, answers from participants were directly used. In the case of open-ended questions, a recoding process was carry-out categorizing answers (etic type) using general descriptors such as food and edibility (abbreviated as $\mathrm{FE})$, venomous and hallucinogenic $(\mathrm{VH})$, healing and medicinal (M), kingdom fungi (F), decomposition and ecological processes (D), bacteria and animal (BA), plant (P) and other $(\mathrm{O})$.

For the analysis, normality within the answer distribution was first tested. A Shannon-Wiener $\mathrm{H}^{\prime}$ calculation was used to test evenness within the answer distribution of selected questions. A Wilcoxon test was used when comparing non-normally distributed numerical variables. Similarly, contingency analyses were performed in the case of nominally structured answers. In the case of two non-normally distributed continuous variables, the Spearman's rho estimate was used for correlation analysis. All statistical analyses were carried out using the statistical package JMP, version 10 (SAS Institute, 2012).

Ethical, conflict of interest and financial statements: The author(s) declare that they have fully complied with all pertinent ethical and legal requirements, both during the study and in the production of the manuscript; that there are no conflicts of interest of any kind; that all financial sources are fully and clearly stated in the acknowledgements section; and that they fully agree with the final edited version of the article. A signed document has been filed in the journal archives.

\section{RESULTS}

Out of the total number of participants, $57,2 \%$ were females and $42,8 \%$ were males. Neither of these values was significantly higher than the approximate 1,02 male: 1.00 female sex distribution in the region. However, some differences in the sex ratio were found within the Honduran dataset (Pearson $c^{2}=26,4$, d.f. $=1, P=0.0001$ ) with $70 \%$ of females. Results showed that about $92 \%$ of participants had intermediate educational level with either complete high school or incomplete university degrees and $75 \%$ of participants were college students. No participants with lack of formal education were recorded and no differences were found in the distribution of educational level between the two populations $(Z=0,52, P=0,60)$. Interestingly, the evenness of the educational level distribution was higher in Costa Rica than in Honduras $\left(H^{\prime}=\right.$ 0,42 vs. 0,33 ).
Perception on the knowledge of what a fungus is: Out of the total number of participants, $92,6 \%$ claimed to know what fungi were. For the two countries evaluated, positive responses were 95,5\% for Costa Rica and 90,1\% for Honduras with no significant differences between the response distributions (Pearsonc ${ }^{2}=7,60$, d.f. $_{=}=3, P=0,06$ ). When analyzed by gender, response patterns for this question did not show significant differences with 86,1 $\%$ of males and $93,0 \%$ of females answering positive to the question. Similarly, when responses were evaluated in terms of country and gender, results showed a lack of differences in the distribution of answers as well (Pearson $c^{2}=12,05$, d.f. $=9, P=0,21$ ). Similar results were obtained for the combined models of country-educational level as well.

\section{Mental associations after hearing the term fungus:} The most common mental associations all participants provided when they heard the word fungus (hongo) were related with the venomous and hallucinogenic and food and edibility categories, with $20,1 \%$ and $17,4 \%$, respectively. After these, the next most common association was that fungi belonged to Kingdom Fungi with $14,7 \%$ of all answers. When the response distribution was analyzed by country, differences were found between participants from both studied areas (Fig. 1), with 24,1\% of Costa Ricans providing answers related with the food and edibility category in comparison with only $16,3 \%$ of Hondurans. Conversely, the most common answers by Hondurans were related with the venomous and hallucinogenic category with $21,1 \%$ against $12,7 \%$ from Costa Ricans. Interestingly, for Hondurans the second most common answer was that fungi were plants with $17,8 \%$, whereas for Costa Ricans the third most common answer (after food and edible and venomous and hallucinogenic) was that fungi were decomposers with $14,8 \%$ of answers. The distribution of answers between Costa Rica and Honduras for this question were significantly different (Pearson $\chi^{2}=49,2$, d.f. $=10, P<0,001$ ).

When responses were analyzed by gender, the most common answers given by both female and male participants were related with the food and edibility category, accounting for $18,9 \%$ and $21,4 \%$ of responses. Interestingly, no combined factor analysis showed significant differences in relation with the response distribution.

Interest of respondents to fungi: Of all participants, $78,2 \%$ agreed that fungi were indeed interesting, $10,3 \%$ disagreed, while the remaining $11,5 \%$ indicated that they did not know. When the analysis was broken down by country and gender, results were similar to the values 


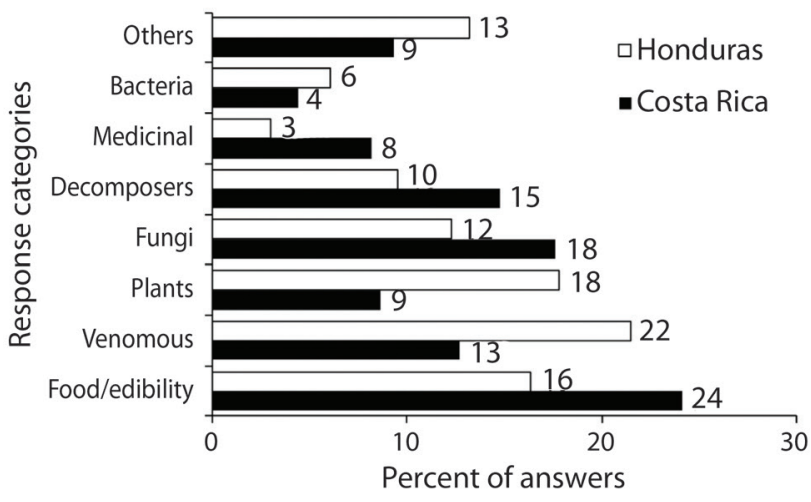

Fig. 1. Percent distribution of mental associations after hearing the term fungus across both studied countries.

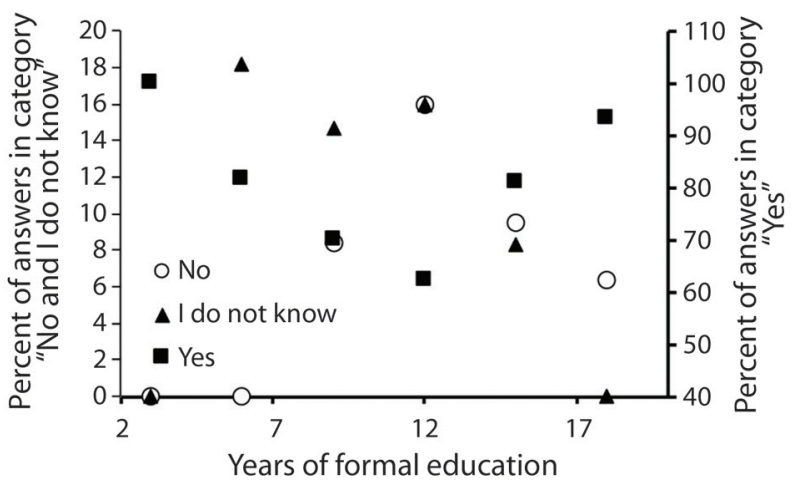

Fig. 2. Percent distribution of interest categories regarding fungi across the educational level of participants.

mentioned above for all subcategories. Both positive and negative answers showed inverse patterns (Fig. 2). The percentage of positive answers increased as a function of post-primary education but was not significant in relation with a randomly generated distribution (Spearman $\rho=0,80, P=0,15)$. When only post-secondary education was observed, the correlation between years of study and positive answers was very high but still not significant (Spearman $\rho=0,99, P=0,07$ ).

Are fungi important for the planet?: The majority of participants $(82,9 \%)$ considered fungi important for our planet. Alternatively, 13,3\% of all surveyed people chose the option I do not know, and negative responses accounted for $2,9 \%$ of all answers. When analyzed by country and gender, response distribution did not show any differences to the above-mentioned values for each subcategory. Similar to our previous topic, a response pattern was observed for both positive and negative answers in relation with level of education. In this case, the percentage of positive answers increased linearly with level of education but did not show significant differences with a randomly generated distribution (Spearman $\rho$ $=0,90, P=0,06$ ) and the percentage of negative answers decreased with the same independent factor (Spearman $\rho=-0,98, P=0,001)$.

Preference for fungi, plants, and animals: For this question, participants were asked to choose their comparative preference regarding fungi, plants and animals, mentioning first the most preferred group. This question generated six possible combined arrangements and considering all participants, the most common one was the sequence animal-plant-fungus (APF) with 52,8\%. The next most common sequences were the plant-animal-fungus (PAF) combination with $21,7 \%$ and the animal-fungus-plant (AFP) combination with $12,1 \%$ of all answers. The two arrangements that called fungi as the most important of all three taxonomic groups accounted for only $3,2 \%$ of responses. Similar patterns occurred for both countries (Fig. 3).

When the analysis was performed only on the answers for the taxonomic group ranked by participants as the most important, results showed that animals and plants were selected more often than fungi in rank one. This analysis also showed that there was a significant correlation between plant and fungi selections (Spearman $\rho=-0,80, P=0,01$ ) demonstrating that participants selected these groups as their preferred in a similar pattern. Rank sequence responses education level did not show any differences with overall distributions.

Most important uses of fungi: Overall distribution of responses to this question showed that $43,9 \%$ of participants provided answers related with the healing and medicinal category and $28,9 \%$ with the food and edibility one. When analyzed by country, results show that the most common responses in Costa Rica were related with the food and edibility category with $38,6 \%$; whereas in Honduras the healing and medicinal option was the most commonly answered with $57,8 \%$ of all answers. As also shown in Fig. 4, the distribution of answers between the two countries was significantly different (Pearson $c^{2}$ $=100,7$, d.f. $=5, P<0,001)$. Contrastingly, the analysis by gender did not show any differences with the overall distribution of responses.

It is relevant that within the studied groups, participants provided high frequencies of answers related with degradation and ecological processes. In Costa Rica, these answers represented $26,9 \%$ of total responses, whereas in Honduras they represented 7,1\%. 


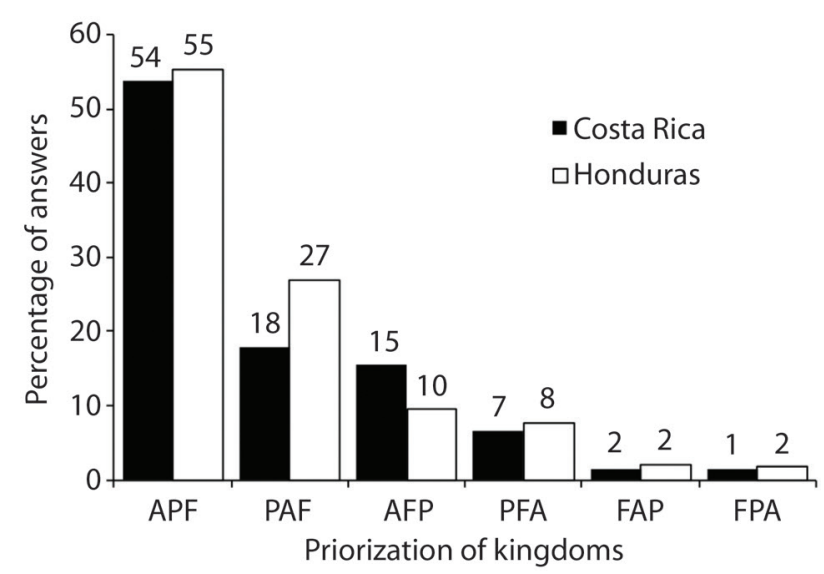

Fig. 3. Priorization of kingdoms by participants across both studied countries. $A=$ animals, $P=$ plants, $F=$ fungi.

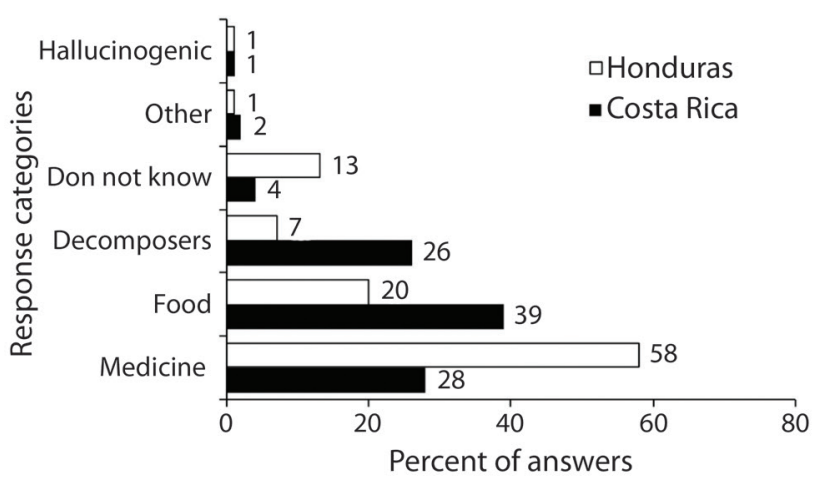

Fig. 4. Percent distribution of response categories associated with fungal uses across both studied countries.

\section{DISCUSSION}

In this study we evaluated perceptions related to fungal resources in young adults presumably associated with two Central American universities. Overall, it was noteworthy that the distribution of educational levels in the Costa Rican dataset was more even than that of the Honduran counterpart. Even though this can be related to known geographical and demographic characteristics of the population in the areas immediately adjacent to the academic institutions (Kaye \& Rumble, 1981), it provided some indication of extent of formal education in those two countries. At first, such differences may account for distinct response distributions. However, in the case of the first question, positive responses were comparatively similar for both study areas indicating that most of the people surveyed had some proximity with fungal resources independent of their background.
Since no differences were found on the general patterns, the majority of the respondents were familiar with fungi. Being one the most common groups on the planet, this was not surprising, especially in tropical areas where the majority of people are acquainted with fungi (Bass \& Richards, 2011). Remarkably, a slightly larger percentage of people not familiar with fungal resources was recorded in Honduras, precisely the country within the Mesoamerican indigenous mycophilic region (Boa, 2004). Urban populations in the two studied countries were more homogeneous than expected, in terms of the perception of fungi.

In spite of such uniformity in answers for the first question, when mental associations were asked, some differences between the two populations were recorded. It was interesting that the most commonly responded categories were the same for the two countries, but their order was switched. The highest frequency of answers for the food and edibility category in Costa Rica was surprising in the context of the a priori hypothesis (see constraints of the approach in Hager, 1996), and the frequency of answers for the venomous and hallucinogenic and the plant categories in both countries seemed to denote the low level of bioliteracy in these social groups since only a small number of fungi are venomous or hallucinogenic and they are obviously not plants. This is important when considering that a large number of commercial products commonly used by people either come from fungi (e.g. some antibiotics) or have used fungi in their industrial formulation (i.e. fermented alcoholic beverages). In the studied populations the terms hongo or hongos (fungus or fungi) were associated with large mushroom-like organisms and not with microscopic groups, showing a bias previously documented by Gómez (1983).

Even though response distributions were different between the two countries and some differences could be found at the gender level, it was also interesting that the category denominated others was recorded at appreciable frequency levels. The latter included answers related with aspects such as video games (i.e. Mario Bros), television shows (i.e. The Smurfs) and other associations (i.e. nuclear bomb cloud shape). For the majority of the participants, such aspects may be part of their daily life considering that cable television and videogame consoles are common among individuals attending college worldwide (Jacobsen \& Forste, 2011).

The high percentage of respondents saying that fungi were interesting seemed to have two explanations. Either, the participants skewed their responses to please the surveyors or in fact the role of formal education in providing tools to discuss a broader range of topics, 
including fungi, was key in this case. It was interesting that there was a switch in the response distribution after 12 years of education, which is around the time most students in Central America attend their first year of college. However, the lack of observable pattern when the analysis was made by country and gender seemed to support the idea that perception of fungal resources may be framed by deeper social factors (Riechers, Barkmann, \& Tscharntke, 2016).

For example, when participants were asked if fungi were important for the planet, an interesting observation was made. Such a question had an element of bias in the grammatical construction itself, but it was useful to evaluate behavioral patterns among surveyed groups. In this case, the mutually exclusive pattern of responses suggested that respondents took the dichotomy approach, which may indicate behavioral conductivism in the populations studied. It seemed that for participants, answers such as yes or no carried a different value than answering I do not know or providing no answer. Even though this was not surprising from a behavioral perspective in Central American populations (Anderson \& Montero-Sieburth, 1998), it may provide an indication of the limited role of education in promoting critical thinking around natural resources. At least for the Costa Rican society there are studies showing a high level of self-perceived green mentality that actually represents a double discourse in practice (Courvisanos \& Jain, 2006).

In spite of the latter and the fact that some people really valued fungal resources and their ecological roles and socioeconomic implications, it was very clear that the familiarity of fungi when compared to animals and plants was very low. There are plenty of documents discussing the anthropocentric view on macroorganisms (Leather, 2009), thus the fact that animals and plants were preferred over fungi was not surprising. Also, Luis Diego Gómez (Gómez, 1983) had already noted that a widespread rejection of fungi was present in most countries in Latin America, presumably as a consequence of the Spanish colony and their imposed views of the world. With few exceptions found in mycophylic Mesoamerican regions, such strong historical-cultural element may have played an important role in the preference for plants and animals observed in the present study.

Responses between the groups on the potential uses of fungi were also worthy of note. Costa Rican respondents preferred the food and edibility category; conversely, the hallucinogenic and venomous one was more common in Honduras. As observed before, the latter answer was preferred by females and since these were the most common participants in Honduras, such a result was somehow expected. However, the higher frequency of Costa Rican answering aspects within the decomposition and ecological processes as well as within the category called others, suggested that this group had more informational resources to provide a response to questions on fungi (Riechers et al., 2016).

In summary, results suggest that exposure to formal education or previous autochthonous cultural background may not play such a central role in shaping perceptions about the group of fungi as social and cultural aspects from colonial times do. In this manner, mycoliteracy could be promoted as a strategy to develop proximity with natural resources to diminish social disconnection with nature (Nisbet \& Zelenski, 2011). Even though both studied groups have different cultural heritage and levels of emotional proximity with natural resources, our results show no significant differences in the perceptional patterns toward fungi . As such, it seemed that homogeneity within urban areas, perhaps due to common history and globalized stimuli, may have played a bigger role in shaping the perceptions recorded herein. This is a very important argument to consider since the development of management strategies in relation with natural resources should be sensitive to socioeconomic and historical differences.

\section{ACKNOWLEDGMENTS}

This project was funded by the University of Costa Rica through Vicerrectoría de Investigación (project 731-B4249 and activity 731-A0-826). Appreciation is extended to Belquis Lemus and Stephanie Somerville for logistic support and assistance with data collection. Finally, we appreciate the suggestions and comments made by one reviewer for the improvement of this manuscript.

\section{REFERENCES}

Anderson, G. L., \& Montero-Sieburth, M. (1998). Educational qualitative research in Latin America: the struggle for a new paradigm. London, England: Routledge.

Bass, D., \& Richards, T. A. (2011). Three reasons to re-evaluate fungal diversity 'on Earth and in the ocean'. Fungal Biology Reviews, 25, 159-164. DOI: 10.1016/j.fbr.2011.10.003

Boa, E. (2004). Wild edible fungi. A global overview of their use and importance to people. Rome, Italy: Food and Agriculture Organization.

Brooks, T. M., Mittermeier, R. A., Mittermeier, C. G., Da Fonseca, G. A. B., Rylands, A. B., Konstant, A. B., Flick, R., Pilgrim, J., Oldfield, S., Magin, G., \& Hilton-Taylor, C. (2002). Habitat Loss and Extinction in the Hotspots of 
Biodiversity. Conservation Biology, 16, 909-923. DOI: 10.1046/j.1523-1739.2002.00530.x

Cohen, J. E. (2003). Human Population: The Next Half Century. Science, 302, 1172-1175. DOI: 10.1126/science.1088665

Cooke, R. (2005). Prehistory of Native Americans on the Central American Land Bridge: Colonization, Dispersal, and Divergence. Journal of Archaeological Research, 13, 129187. DOI:10.1007/s10804-005-2486-4

Courvisanos, J., \& Jain, A. (2006). A Framework for Sustainable Ecotourism: Application to Costa Rica. Tourism and Hospitality Planning \& Development, 3, 131-142. DOI: 10.1080/14790530600938378

Diedrich, A., \& García Buades, E. (2009). Local Perceptions of Tourism as Indicators of Tourism Destination Decline. Tourism Management, 30, 512-521. DOI: 10.1016/j. tourman.2008.10.009

Gómez, L. D. (1983). De Fungi. Una selección de Plinio el Viejo. Brenesia, 21, 437-447.

Hager, W. (1996). On testing a priori hypotheses about quantitative and qualitative trends. Methods of Psychological Research Online, 1, 1-23.

Hall, C., \& Pérez Brignoli, H. (2005). Historical Atlas of Central America. Oklahoma, USA: University of Oklahoma Press.

Jacobsen, W., \& Forste, R. (2011). The Wired Generation: Academic and Social Outcomes of Electronic Media Use Among University Students. Cyberpsychology, Behavior, and Social Networking, 14, 275-280. DOI: 10.1089/ cyber.2010.0135.

Joppa, L. N., Roberts, D. L., Myers, N., \& Pimm, E. L. (2011). Biodiversity hotspots house most undiscovered plant species. PNAS, 108, 13171-13176. DOI: 10.1073/ pnas. 1109389108.
Kaye, A., \& Rumble, G. (Eds.). (1981). Distance teaching for higher and adult education. London,England: Routledge.

Lange, L. (2010). The importance of fungi for a more sustainable future on our planet. Fungal Biology Reviews, 24, 90-92. DOI: 10.1016/j.fbr.2010.12.002.

Larson, S., De Freitas, D. M., \& Hicks, C. C. (2013). Sense of place as a determinant of people's attitudes towards the environment: Implications for natural resources management and planning in the Great Barrier Reef, Australia. Journal of Environmental Management, 117, 226-234. DOI: 10.1016/j.jenvman.2012.11.035.

Leather, S. R. (2009). Taxonomic chauvinism threatens the future of entomology. Biologist, 56, 10-13.

Lennox, J., ed. (2010). The Economics of Climate Change in Central America: Summary 2010. México D.F., México: CEPAL.

Naeem, S. Duffy, J. E., \& Zavaleta, E. (2012). The Functions of Biological Diversity in an Age of Extinction. Science, 336, 1401-1406. DOI:10.1126/science.1215855.

Nisbet, E. K., \& Zelenski, J. M. (2011). Underestimating Nearby Nature: Affective Forecasting Errors Obscure the Happy Path to Sustainability. Psychological Science, 22, 11011106. DOI: $10.1177 / 0956797611418527$.

Obando, V. (2007). Biodiversidad de Costa Rica en Cifras. Santo Domingo de Heredia, Costa Rica: INBio.

Parker, J. S. (2011). John Schelhas and Max J. Pfeffer: Saving forests, saving people? Environmental conservation in Central America. Agriculture and Human Values, 28, 289290. DOI:10.1007/s10460-011-9313-2

Riechers, M., Barkmann, J., \& Tscharntke, T. (2016). Perceptions of cultural ecosystem services from urban green. Ecosystem Services, 17, 33-39. DOI: 10.1016/j.ecoser.2015.11.007

SAS Institute. (2012). JMP [computer software]. Cary, North Carolina, USA: SAS Institute. 